\title{
A cross-continental comparison of assemblages of seed- and fruit- feeding insects in tropical rain forests: faunal composition and rates of attack
}

by Basset, Y., Dahl, C., Ctvrtecka, R., Gripenberg, S., Lewis, O.T., Segar, S.T., Klimes, P., Barrios, H., Brown, J.W., Bunyavejchewin, S., Butcher, B.A., Cognato, A.I., Davies, S., Kaman, O., Knizek, M., Miller, S.E., Morse, G.E., Novotny, V., Pongpattananurak, N., Pramual, P., Quickes, D.L.J., Robbins, R.K., Sakchoowong, W., Schutze, M., Vesterinen, E.J., Wang, W., Wang, Y., Weiblen, G. and Wright, J.S.

Copyright, publisher and additional information: this is the author accepted manuscript. The final published version (version of record) is available online via Wiley. This article may be used for non-commercial purposes in accordance with Wiley Terms and Conditions for Self-Archiving.

Please refer to any applicable terms of use of the publisher.

DOI: https://doi.org/10.1111/jbi.13211 


\section{A cross-continental comparison of assemblages of seed- and fruit-feeding insects in tropical rainforests: faunal composition and rates of attack}

Running title: Insects feeding on seeds in rainforests

Yves Basset ${ }^{1,2,3,4^{*}}$, Chris Dahl ${ }^{2,3}$, Richard Ctvrtecka ${ }^{2,3}$, Sofia Gripenberg ${ }^{5}$, Owen T. Lewis ${ }^{5}$, Simon T. Segar ${ }^{2,3}$, Petr Klimes ${ }^{3}$, Héctor Barrios ${ }^{4}$, John W. Brown ${ }^{6}$, Sarayudh Bunyavejchewin ${ }^{7}$, Buntika A. Butcher ${ }^{8,9}$, Anthony I. Cognato ${ }^{10}$, Stuart Davies ${ }^{11}$, Ondrej Kaman $^{2,3}$, Milos Knizek ${ }^{12}$, Scott E. Miller ${ }^{6}$, Geoffrey E. Morse ${ }^{13}$, Vojtech Novotny ${ }^{2,3}$, Nantachai Pongpattananurak ${ }^{14}$, Pairot Pramual ${ }^{15}$, Donald L.J. Quicke ${ }^{8}$, Robert K. Robbins ${ }^{6}$, Watana Sakchoowong ${ }^{16}$, Mark Schutze ${ }^{17}$, Eero J. Vesterinen ${ }^{18}$, Wenzhi Wang ${ }^{19,20,21}$, Yun-yu Wang ${ }^{19}$, George Weiblen ${ }^{22} \&$ Joseph S. Wright ${ }^{1}$

${ }^{1}$ Smithsonian Tropical Research Institute, Apartado 0843-03092, Balboa, Ancon, Panamá.

${ }^{2}$ Faculty of Science, University of South Bohemia, 37005 Ceske Budejovice, Czech Republic.

${ }^{3}$ Biology Centre of the Czech Academy of Sciences, Institute of Entomology, 37005 Ceske Budejovice, Czech Republic.

${ }^{4}$ Maestria de Entomologia, Universidad de Panamá, 080814 Panama City, Republic of Panama.

${ }^{5}$ Department of Zoology, University of Oxford, Oxford OX1 3PS, U.K.

${ }^{6}$ National Museum of Natural History, Smithsonian Institution, Box 37012, Washington, DC 20013-7012, USA.

${ }^{7}$ Research Office, Department of National Parks, Wildlife and Plant Conservation, Bangkok 10900 Thailand.

${ }^{8}$ Integrative Ecology Laboratory, Department of Biology, Faculty of Science, Chulalongkorn University, Phayathai Road, Pathumwan, BKK 10330, Thailand.

${ }^{9}$ Center of Excellence in Entomology: Bee Biology, Diversity of Insects and Mites, Chulalongkorn University, Phayathai Road, Pathumwan, BKK 10330, Thailand.

${ }^{10}$ Department of Entomology, Michigan State University, Natural Science Bldg., 288 Farm Lane Room 445A, East Lansing, MI 48824, U.S.A.

${ }^{11}$ Center for Tropical Forest Science-Forest Global Earth Observatory, Smithsonian Tropical Research Institute, P.O. Box 37012, Washington 20013, USA.

${ }^{12}$ Forestry and Game Management Research Institute, Strnady 136, CZ - 25202 Jíloviště, Czech Republic.

${ }^{13}$ Biology Department, University of San Diego, 5998 Alcalá Park, San Diego, CA 92110, U.S.A.

${ }^{14}$ Department of Forest Biology, Faculty of Forestry, Kasetsart University, 50 Ngam Wong Wan Rd, Lat Yao Chatuchak, Bangkok 10900, Thailand. 
${ }^{15}$ Department of Biology, Faculty of Science, Mahasarakham University, Kantharawichai District, Maha Sarakham 44150, Thailand.

${ }^{16}$ Forest Entomology Group, Department of National Parks, Wildlife and Plant Conservation, Praholyothin Road, Chatujak, Bangkok 10900. Thailand.

${ }^{17}$ School of Earth, Environmental \& Biological Sciences, Queensland University of Technology, GPO Box 2434, Brisbane, QLD 4001, Australia.

${ }^{18}$ Department of Agricultural Sciences \& Department of Biology, PO Box 27, FI-00014 University of Helsinki, Finland.

${ }^{19}$ State Key Laboratory of Genetic Resources and Evolution, Kunming Institute of Zoology, Chinese Academy of Sciences, 32 Jiaochang Donglu, Kunming, China 650223.

${ }^{20}$ Guizhou Academy of Testing and Analysis, 99 Baoshan S. Rd., Guiyang, China 550002.

${ }^{21}$ Forensic Science Services of Yunnan Endangered Species Scientific Commission, 21 Qingsong Rd., Kunming, China 650203.

${ }^{22}$ Bell Museum and Department of Plant and Microbial Biology, University of

Minnesota, 1479 Gortner Avenue, St. Paul, Minnesota, 55108-1095 U.S.A.

${ }^{*}$ Correspondence: Yves Basset, Smithsonian Tropical Research Institute, Apartado 0843-03092, Balboa, Ancon, Panamá. E-mail: bassety@si.edu

\section{ACKNOWLEDGEMENTS}

We thank the Smithsonian Tropical Research Institute (Panama), Khao Chong Botanical Garden (Thailand) and Binatang Research Centre and Wanang Conservation Area (Papua New Guinea) for logistical support. D. Catalina Fernandez, Indira Simon Chaves, Marjorie Cedeño, Marleny Rivera (Panama), Pitoon Kongnoo, Montarika Panmeng, Sutipun Putnaul (Thailand), Dominic Rinan, Jonah Philips, Roll Lilip and Ruma Umari (Papua New Guinea) collected most of the insect material. This study was supported by the Czech Science Foundation (16-20825S). Field work on BCI was largely funded by a postdoctoral grant from the Academy of Finland to SG. Grants from the Smithsonian Institution Barcoding Opportunity FY013 and FY014 (to YB), from the ForestGEO Research Grant Program (to CD), and in-kind help from the Canadian Centre for DNA Barcoding and Southern China DNA Barcoding Center allowed to sequence insect specimens. Taxonomists listed in Table S2 helped with insect identification. YB and HB are members of the Sistema Nacional de Investigación, SENACYT, Panama. SG holds a Royal Society University Research Fellowship. MK was partly supported by the Ministry of Agriculture of the Czech Republic (Resolution 
RO0117; 6779/2017-MZE-14151). DLJQ and BAB were supported by Ratchadaphiseksomphot Fund, Chulalongkorn University (respectively Senior Postdoctoral Fellowship and Endowment Fund R/F_2559_019_05_23).

\section{ABSTRACT}

Aim Insects feeding on seeds and fruits represent interesting study systems, potentially able to lower the fitness of their host plants. In addition to true seed eaters, a suite of insects feed on the fleshy parts of fruits. We examined the likelihood of community convergence in whole insect assemblages attacking seeds/fruits in three tropical rainforests.

Location Three ForestGEO permanent forest plots within different biogeographical regions: Barro Colorado Island (Panama), Khao Chong (Thailand) and Wanang (Papua New Guinea).

Methods We surveyed 1,186 plant species and reared 1.1 ton of seeds/fruits that yielded 80,600 insects representing at least 1,678 species. We assigned seeds/fruits to predation syndromes on the basis of plant traits relevant to insects, seed/fruit appearance and mesocarp thickness.

Results We observed large differences in insect faunal composition, species richness and guild structure between our three study sites. We hypothesize that the high species richness of insect feeding on seeds/fruits in Panama may result from a conjunction of low plant species richness and high availability of dry fruits. Insect assemblages were weakly influenced by seed predation syndromes, both at the local and regional scale, and the effect of host phylogeny varied also among sites. At the driest site (Panama), the probability of seeds of a plant species being attacked depended more on seed availability than on the measured seed traits of that plant species. However when seeds were attacked, plant traits shaping insect assemblages were difficult to identify and not related to seed availability.

Main conclusions We observed only weak evidence of community convergence at the intercontinental scale among these assemblages. Our study suggests that seed eaters may be most commonly associated with dry fruits at relatively dry tropical sites where fleshy fruits may be less prevalent.

Keywords convergence, guild structure, pulp eater, seed predator, seed rain, seed syndrome, species richness. 
INTRODUCTION

Convergent evolution (or convergent phenotypic evolution: Mahler et al., 2017) refers to the independent evolution of similar traits in different lineages resulting from strong selective pressures. Convergence is also recognized in ecological assemblages, and community convergence may be defined as the similarity in community structure or physiognomy of assemblages of cooccurring plants or animals resulting from comparable physical and biotic selective pressures (Schluter, 1986; Samuels \& Drake, 1997; Smith \& Wilson, 2002; Bittleston et al., 2016). Hence community (or ecological) convergence can be sought in terms of (a) search for similarities in patterns of biodiversity and community structure, including species richness, relative abundance distributions, occurrence of trophic guilds, or (b) convergence in the characters of the species present (Smith \& Wilson, 2002; Korňan et al., 2013; Segar et al., 2013). In this contribution, we focus on the former aspect of community convergence.

Several mechanisms have been proposed to explain community convergence. First, the likelihood of convergence may be driven by ecological opportunity, which may be based on what resources are in excess and can be easily employed (Agrawal, 2017). Second, biotic filtering, mostly based on species interactions, can result in community-level convergence (Smith \& Wilson, 2002). Eventually, communities may reach similar ecological structure through different phylogenetic structures. In this case empty niches are filled through a combination of colonisation by pre-adapted species and/or niche shifts by resident lineages (Gillespie, 2004; Segar et al., 2013). Segar et al. (2013) demonstrated this mechanism for intercontinental fig wasps assemblages.

Of particular interest are examples of community convergence involving assemblages developing on different continents but under similar environmental conditions (Samuels \& Drake, 1997). Community convergence on different continents has been reported for a variety of plant communities (Samuels \& Drake, 1997) and vertebrate taxa. For the latter, convergence was observed with regard to morphology (fishes: Winemiller, 1991; birds: Ricklefs \& Travis, 1980; mammals: Mares, 1993) or species richness (fishes: Irz et al., 2007; birds: Schluter, 1986). Yet convergence is often evidenced at rather coarse levels, such as guilds (a group of species that exploit the same class of resources in a similar way: Root, 1973), as opposed to finer levels of scale such as species composition (Samuels \& Drake, 1997; Korňan et al., 2013). One explanation may be that environmental conditions may determine the types of available niches and therefore the functional groups that can fill them, while species compositions within functional groups are influenced stochastically by the history of species arrivals (Fukami et al., 2005).

It has been repeatedly demonstrated that assemblages of invertebrates, particularly arthropods, are rather different from those of vertebrates or plants, as including finer-grained patch sizes and geographic distributions, more complex seasonal and successional sequences, and more rapid generation turnover (Kremen et al., 1993). As a consequence, community convergence is more likely 
in vertebrates than invertebrates, since the latter are generally more closely tied to the specifics of their resources (Samuels \& Drake, 1997). Nevertheless, convergence in arthropod communities has been observed in series reflecting island colonization (Gillespie, 2004), secondary succession (Hendrix et al., 1988), habitat restoration (Watts et al., 2008), or in assemblages submitted to intense interspecific competition for patchy and ephemeral food resource, such as dung beetles (Inwards et al., 2011).

Convergent evolution of phytophagous insects is indicated, for example, by resistance to plant toxins, such as cardiac glycosides (Petschenka et al., 2017). In contrast, lack of community convergence appears to be common in many phytophagous insect communities. This may result from host plants being sufficiently biochemically and structurally different to prevent certain modes of feeding or from interspecific competition being too weak to induce convergence (Lawton, 1984). One notable exception includes assemblages of highly specific fig wasps and their parasitoids enclosed in fig syconia. Segar et al. (2013) confirmed intercontinental community convergence in guild proportionality for these assemblages and predicted that similar examples could be observed for bounded communities with well-defined resource units, such as insect herbivores feeding on fruits.

Insects feeding on seeds and fruits represent tractable study systems for studying community convergence. In addition to true seed predators, a suite of insects (notably Diptera and Lepidoptera) feed on the fleshy parts of fruits (Ctvrtecka et al., 2016). The study of these insect assemblages can provide important information on how insect assemblages are structured in hyperdiverse tropical communities. Yet we know very little about the basic biology and ecology of insect herbivores in tropical rainforests, with, specifically, only a handful of studies documenting whole assemblages of seed/fruit feeders (Nakagawa et al., 2003; Ctvrtecka et al., 2014, 2016; Sam et al., 2017).

Following the results of Segar et al. (2013), we ask whether intercontinental convergence in discrete and specialist communities could be generalized to insects feeding on seeds and fruits in different tropical rainforests. While the barriers to community membership are weaker for seed and fruit feeding insects, these communities are still bounded. Because of the high diversity and phylogenetic extent of these assemblages (see results), we took a simplistic approach in testing for differences in insect variables most likely to reflect community convergence, such as species richness and guild proportionality. Our general objectives were to test whether assemblages of insects feeding on seeds/fruits in three representative rainforests within different biogeographical regions (Neotropical, Oriental and Australian) converged towards predictable patterns of community structure influenced by plant phylogeny and/or plant functional traits ('seed predation syndromes', see methods). 
We specifically aim at answering three key questions, derived from mechanistic hypotheses from the literature on plant-insect interactions (reviews in Strong et al., 1984; Lewinsohn et al., 2005):

i) Are the community attributes of insect assemblages feeding on seeds/fruits (abundance, higher taxonomic composition, guild structure and species richness) similar, both at local and inter-continental scales, and when controlling for plant phylogeny? Further, can plant and seed traits predict the characteristics of these insect assemblages?

The classic defence and plant apparency theory postulates that that the breadth of an herbivore's diet depends upon the apparency and mode of defence of its food-plant (Feeny, 1976). Under this hypothesis, the species richness of seed/fruit predator assemblages is expected to be similar for sets of host plants with particular functional traits, irrespective of plant family, provided that host traits are reasonably independent of plant phylogeny. The defence theory has been modified several times and is now part of a framework of three syndromes of plant defence, including (1) tolerance/escape, (2) low nutritional quality and (3) high nutritional quality and defence (Agrawal \& Fishbein, 2006). Considering the antagonism between seeds and seed predators, fleshy fruits may represent an analogy with the tolerance/escape syndrome, as they are quickly dispersed by frugivores, while dry fruits (achenes) may be more likely to be nutritious but well defended against seed predators. If community convergence exists in assemblages of insects feeding on seeds/fruits then we would expect community attributes to be influenced by seed predation syndromes (see Methods), including fruit fleshiness, and to be similar across locations.

ii) Do rare tree species support less abundant, less diverse or functionally distinct seed/fruit feeding insect assemblages than common tree species?

The encounter frequency and resource concentration hypotheses state that more widespread or more locally abundant tree species may support a more abundant and richer herbivore fauna (Root, 1973; Kelly \& Southwood, 1999). These hypotheses likewise predict differences in the species richness of seed/fruit feeder assemblages supported by rare and common host trees. Further, if community convergence exists at continental scale, we would at least expect similarity in some of the community attributes between insect assemblages feeding on seeds/fruits of common tree species, as resources may be easily exploited in this case (Agrawal, 2017).

iii) Are seed predation rates lower in forests of higher floristical diversity, do these rates vary among plant families, and can they be predicted from plant and seed traits? 
Plant resource in floristically diverse tropical forests may be difficult to track for insect herbivores and result in relatively low host specificity in these forests (Novotny et al., 2002). Since abundant and specialized insect feeders are responsible for most of plant damage (Coley \& Barone, 1996), we predict lower seed predation rates in floristically more diverse forests and/or within more diverse plant families. If the likelihood of community convergence depends to some extent on the ease of tracking resources (Agrawal, 2017), then we would also expect plant species richness to be one of the key factors shaping similarities in insect assemblages feeding on fruits/seeds.

\section{MATERIALS AND METHODS}

\section{Study sites}

Our study sites are three ForestGEO lowland rainforest plots (Anderson-Teixeira et al., 2014), located in different biogeographical regions (Table S1). These sites are detailed in Anderson-Teixeira et al. (2014), salient characteristics of the vegetation plots are also summarized in Table S1 and in Appendix S1, and maps can be consulted at http://www.forestgeo.si.edu/. Neotropical: Barro Colorado Island (BCI) is a 1,500 ha island created by the opening of the Panama Canal in 1914 . The 50 ha plot is located in the center of the island, which is a biological reserve. Oriental: the 24 ha plot at Khao Chong (KHC) is located in the protected forest of the Khao Ban Thad Wildlife Sanctuary in Southern Thailand. Australian: the 50 ha plot is located within the 10,000 ha Wanang Conservation Area in Papua New Guinea (WAN).

\section{Plant surveys}

Field methods were similar for all study sites. Plant surveys spanned 3-4 years at each site (Table S1). During the first study year at each site, we surveyed seeds and fruits of locally abundant tree, shrub and liana (more rarely herb) species. During subsequent study years, we restricted our sampling effort to 10 plant families, which represented the most common families at each plot (8 families were common to all sites, 2 other families were well represented locally). We refer to these families as focal families and they included at all plots: Annonaceae, Arecaceae, Euphorbiaceae, Fabaceae, Lauraceae, Meliaceae, Rubiaceae, Sapindaceae; at BCI: Bignoniaceae, Clusiaceae; at KHC: Ebenaceae, Phyllanthaceae; at WAN: Myristicaceae, Myrtaceae. Unless specified, results are detailed for all host plant species. Seeds and fruits collected on plants or freshly fallen (without apparent decomposition) were surveyed within and/or near permanent plots (from an area $<1,500$ ha corresponding to the smallest study area, BCI). Rearing sample units included clusters of conspecific seeds/fruits of similar size collected from the same trees. We targeted as many individuals as possible for each plant species, typically $>5$. These sample units were weighted (fresh weight) and stored in individual plastic pots (details in Table 1 and Appendix S1). 
Insect rearing and processing

Rearing pots were stored under semi-natural conditions in covered but ventilated sheds under the forest canopy. They were checked twice weekly, and any emerging insect was collected, preserved, mounted and then identified with the assistance of taxonomists (see Table S2) and/or with molecular techniques. We obtained DNA Cytochrome c oxidase subunit I (COI, 'DNA barcode') sequences from legs of representative insect specimens and we used Barcode Index Numbers (BINs) derived from insect sequences to delineate species (Ratnasingham et al., 2013). Data were deposited in different Barcode of Life projects (details in Appendix S1).

Insects reared from seeds/fruits were assigned to the following guild categories, inspired from Moran and Southwood (1982): seed eaters (coded as SE: larva feeding mostly on seed tissue), pulp eaters (PU: larva feeding mostly on mesocarp tissue), scavengers (SC: larva feeding mostly on decaying matter), fungal feeders (FU: larva feeding mostly on fungi) and parasitoids (PA: larva feeding on insect hosts). Guild assignment was done mostly at the familial or subfamilial level, but in some case at the generic or specific level, as indicated in Table S2 and Appendix S1.

\section{Measurement of plant traits and rates of seed attack}

Host plants were identified and a suite of plant traits was determined as far as possible for each plant species, including: plant life form (tree, shrub, liana, herb, palm), seed syndrome, species abundance (no. of stems or basal area in vegetation plots), seed rain, seed fresh mean weight and mean length, and rates of seed attack (see below). Seeds and fruits exhibit a diversity of morphological and ecological features, which may represent important determinants of host use in seed- and fruit-feeding insect taxa. We selected eight putative seed predation syndromes (in analogy with 'flower syndromes': Barth, 1981) on the basis of (a) plant traits particularly relevant to insects (Janzen, 1969; Ramírez \& Traveset, 2010); and (b) previous comparisons of the distribution of seed/fruit categories at our three study sites (C. Dahl et al., unpubl. data). Each plant species was assigned a seed syndrome on the basis of seed/fruit appearance (fleshiness and dehiscence), number of seeds per fruit and measurement of mesocarp thickness (Table 2). Beside host chemistry and odor, these traits represent important variables for ovipositing female insects and the developing larvae (Messina, 1984; Díaz-Fleischer et al., 2000). This classification of seed syndromes is compared elsewhere with other systems used in botany (based on morphology and mode of dispersal) and in vertebrate zoology (frugivory)

(C. Dahl et al., unpubl. data). Seed rain was estimated using weekly censuses of litter traps (Wright et al., 2004; Appendix S1). Rates of seed attack may be derived with different approaches. Here, we consider an entomocentric view including, for each plant species, either the average number of seed eaters reared per seed or the percentage of seed attacked. The former has been identified as a critical factor for seed germination (Nakagawa et al., 2003) and we refer to the latter as the "apparent rate of seed 
attack". Average values for most plant traits at the community level (i.e., average for all plant species surveyed) are detailed in Table 1.

\section{Statistics: question (i)}

For answering this question, our analyses aimed at evaluating differences in insect community structure between our study sites. Differences in insect variables suggest lack of community convergence, while a high similarity does not necessarily indicate community convergence. Sampling effort, either expressed as the number of seeds collected or the weight of samples, was significantly different between sites (Table S1). To account for this situation, our analyses considered average proportions within samples, rarefaction, or expressed insect variables per unit seed or unit g fresh weight, for comparisons among study sites (see Appendix S1 for details). To compare insect faunal composition and species richness, we considered the following taxa, which were well studied, represented $48 \%$ of the total material collected, and were also observed as important seed/fruit feeders in other tropical community studies (Ramírez \& Traveset, 2010; Ctvrtecka et al., 2016): Bruchinae, Scolytinae, Curculionidae others than Scolytinae (Coleoptera), Tortricidae, Pyralidae (Lepidoptera), Stratiomyidae, Tephritidae (Diptera) and Braconidae (Hymenoptera). We evaluated differences across sites with Kruskal-Wallis tests, after a logit transformation (Warton \& Hui, 2011). Faunal similarity was estimated with the Morisita-Horn index calculated with the 'vegan' library of the R-language (Oksanen et al., 2011), separately for each main guild on the basis of the abundance of insect families at each site. We tested for differences in the distribution of insect guilds across seed syndromes and sites with contingency analysis.

To evaluate the possible existence of clusters formed by insect guilds and seed syndromes, we performed correspondence analyses (CA) for each site on the matrices of the abundance of the main insect guilds (seed eaters, pulp eaters, fungal feeders, scavengers, parasitoids) ordered by plant species (all plant species surveyed, 264, 237 and 257 species for BCI, KHC and WAN, respectively). These and other multivariate analyses (see below) were performed with Canoco 5.04 (ter Braak \& Smilauer, 2012 ). We compared species richness (measurements of species diversity or evenness are less relevant in this context) for these same insect groups among study sites by computing rarefaction and extrapolation sampling curves of species richness with the $\mathrm{R}$ package iNEXT (Hsieh et al., 2016). We considered the following data sets for comparing insect groups: all plant data available, data restricted to the 10 plant focal families and data restricted to BINs. We also compared total species richness separately for each study site and seed syndrome, with all plant data. With the same software we calculated an estimated asymptotic species richness (Hsieh et al., 2016). 
Statistics: testing the influence of plant and seed traits on insect assemblages

We estimated the phylogenetic relationships between our focal host species using the software package Phylomatic (Webb \& Donoghue, 2004; details in Appendix S1). We used a variance partitioning approach (Dray et al., 2006) to quantify the contribution of our explanatory variables (plant traits) and host phylogeny to structuring the composition of insect communities across plant hosts at each site, using Canonical Correspondence Analysis (CCA; details in Appendix S1). We used the following plant traits for each plant species: life form, seed syndrome, seed type (as binary trait dry or fleshy), weight and length, and number of seeds per fruit. To obtain a balanced design, the analyses were restricted to the 10 focal plant families and to host species for which all measured variables were available. The representation of phylogeny through eigenvectors does not always capture phylogenetic structure fully (Freckleton et al., 2011). Hence we tested the influence of seed traits on insect community structure (i.e. presence of species') using a more explicit phylogenetic comparative framework: binomial Phylogenetic Linear Mixed Models (PGLMM) (Ives \& Helmus, 2011). Insect presence (response variable) was modeled using separate models for the traits: fruit length, number of seeds, fresh fruit weight and seed type (fixed explanatory variables), while including insect and host species identities as random effects. We included phylogenetic covariation as an additional random effect. We used the R package pez (Pearse et al., 2015) to construct PGLMM's (fitting models using restricted maximum likelihood; see Appendix S1).

\section{Statistics: question (ii)}

Common and rare tree species were defined as belonging to the first and last quartiles of abundance, respectively (Gaston, 1994), within each ForestGEO plot (vegetation data, Appendix S1). We compared the average abundance (all insects and seed eaters), species richness (rarefaction method as previously) and guild structure of all insects (proportion of individuals) reared from tree species belonging to the first and last quartile of abundance in vegetation plots. We tested for differences in guild structure in common tree species between different sites with contingency analysis.

\section{Statistics: question (iii)}

To evaluate differences in seed attack rates, we used the logit transformation (cf. above) to transform the apparent rate of seed attack and tested the significance of factors site and seed syndrome in a two way ANOVA. We performed a similar analysis with $\log$ transformed abundance of seed eaters reared per unit seed. For each site, we analyzed the statistical relationship between all continuous independent variables included in the multivariate analyses and the dependent variable presence/absence of seed eaters reared from all plant species surveyed (1/0), using quasibinomial generalized linear models (GLMs). We controlled for the phylogenetically non-independent data points as explained in Appendix S1. Further when seeds were attacked, we quantified the influence of continuous independent variables on three dependent variables (average number of seed eaters per unit seed, apparent rate of seed attack and number of species of seed eaters reared), using phylogenetic path analysis (PPA; Gonzalez-Voyer \& von 
Hardenberg, 2014). The procedure and the assumptions of the models, which were calculated with the R package phylopath

(van der Bij1, 2017), are detailed in Appendix S1 and Fig. S1. Eventually, to evaluate the possible effect of plant species richness on seed attack, we considered (a) the results of the GLMs described above, with the number of confamilial species for each plant species included as independent variable; and (b) the relation between the number of confamilial plant species and the average percentage of seed attack per plant genus at each study site. In this case, considering plant genera instead of plant species reduced the possible effects of host phylogeny on the independence of data points.

\section{RESULTS}

\section{Differences in the composition, guild structure and species richness of insect assemblages}

At the three sites $1,163 \mathrm{~kg}$ of seeds/fruits were reared, which yielded 80,600 insects representing at least 1,678 species reared from 1,186 plant species (Tables 1 and S1). Details about the salient differences between study sites in terms of plant and insect variables are further reported in Appendix S2. Average proportions per sample of particular taxa or guilds were all significantly different across sites (Figs 1, S2), with sometimes higher taxa absent at particular sites (Table S2). Generally the highest faunal similarity was recorded between KHC and WAN (Table S3). Most insect reared were assigned to pulp eaters (present in 8-34\% of samples), scavengers (6-25\%) and seed eaters (11-13\%), and this general pattern was similar across sites and when restricting the data to the 10 focal plant families (Figs 1 and S2). Seed eaters overall represented $44.3 \%$ of all insects reared at BCI, whereas this percentage was only $14.2 \%$ and $14.3 \%$ at KHC and WAN, respectively. These general patterns were broadly similar for data restricted to 10 plant families, but with notable exceptions for the Curculionidae (Fig. S2).

When all three study sites were considered together, it was apparent that a high relative proportion of Bruchinae and of seed eaters were reared from dry fruits (categories B2, C1 and C2, see Ramírez \& Traveset, 2010), whereas a high relative proportion of Tephritidae and scavengers were reared from fleshy fruits (Fig. S3; see Copeland et al., 2009). The highest and lowest relative proportion of seed eaters reared originated from categories $\mathrm{C} 1$ and A1.1-B2, respectively. The distribution of insect guilds across seed syndrome categories was significantly non-uniform within each site (BCI, Chisq. = 5,589.6; KHC, Chisq. = 1,695.3; WAN, Chisq. $=3,935.8$; all with $\mathrm{p}<0.001$ ), but appeared more resembling when comparing KHC and WAN data than when comparing BCI data with other sites (Fig. 2). The proportion of plant species with dry fruits was higher at BCI (Table S1), but seed eaters were reared from a variety of syndrome categories, not just dry fruits (Table 2). This was confirmed by the large spread of insect guilds across seed syndrome categories, with no obvious clusters around guilds (CA, Fig. S4). The distributions of insect guilds within syndrome categories were significantly non-uniform across sites, even when only drupes were considered $($ Chisq. $=$ 7,639.2, $\mathrm{p}<0.001$ ), fleshy fruits (Chisq. $=9,308.4, \mathrm{p}<0.001)$ or dry fruits (Chisq. $=3,781.5, \mathrm{p}<0.001$; Fig. 2, Table 2). 
Overall insect species richness reared from samples followed the series BCI (total number of species observed $=1,178 /$ number of species of seed eaters $=311)>$ WAN $(462 / 77$ spp. $)>$ KHC (378 / 60 spp.). Rarefaction and asymptotic estimators indicated that BCI was the most species-rich site when considering all data and BINs. For the 10 focal species, species richness at BCI and WAN appeared to be similar (Fig. S5). For seed syndromes surveyed with relatively high sample size, insect species accumulated faster on dry seeds/fruits at $\mathrm{BCI}(\mathrm{C} 2>\mathrm{B} 2>\mathrm{A} 1.2)$, whereas this pattern was opposite at $\mathrm{KHC}(\mathrm{B} 1>\mathrm{A} 1.2>\mathrm{C} 2)$ and WAN $(\mathrm{A} 1.2>$ A1.1 > B2; Fig. S6).

\section{Influence of plant traits and phylogeny}

The proportion of overall variance in insect faunal composition that was explained by all the explanatory variables in the CCAs was significant and relatively consistent (12.6-18.7\% after excluding singletons; Table S4), with seed syndrome, seed length and number of seeds, as best explanatory variables (Fig. 3). However, the effects of host phylogeny (both overall and exclusive after controlling for plant traits) were much more variable among sites, ranging from 3.2\% (BCI) to $72 \%$ (WAN) (Table S4). The results using binary occurrence of insect species (PGLMM) mirrored the multivariate CCAs but also confirmed the difficulty to predict insect faunal composition with plant traits. Seed type (dry/fleshy) did not influence faunal composition for any site. Still, fresh fruit weight had a significant positive relationship with the response variable for KHC (Table S5).

\section{Insect assemblages on rare and common tree species}

Significantly more insects and seed eaters were reared from rare tree species than from common tree species at BCI (MannWhitney tests, $U=30.87, p>0.001$ and $U=6.26, p=0.012$, respectively, $n 1=1044, n 2=66$; Fig. 4). This pattern was opposite at WAN for seed eaters $(U=4.54, \mathrm{p}=0.033, \mathrm{n} 1=1036, \mathrm{n} 2=55)$ but not significant for all insects $(\mathrm{U}=0.67, \mathrm{p}=0.41)$. At KHC, neither the abundance of all insects nor of seed eaters was significantly different between common and rare trees $(U=0.08, p=0.78$ and $\mathrm{U}=0.06, \mathrm{p}=0.81$, respectively, $\mathrm{n} 1=392, \mathrm{n} 2=57$; Fig. 4). The rate of species accumulation was difficult to compare between common and rare trees, because of the relatively small sample of the latter, but extrapolations suggested that common tree species accumulated more species than rare tree species at all study sites (Fig. S7a). The guild structure of common tree species was significantly non-uniform between study sites (Chisq. $=3721.6, \mathrm{p}<0.001 ;$ Fig. $7 \mathrm{~b})$. Further, the guild structure of insects reared from common and rare tree species was similar at KHC and WAN, but the proportion of seed eaters vs. other insects was significantly non-uniform across these tree categories at BCI (Fisher exact test, $\mathrm{p}<0.001 ;$ Fig. S7b).

\section{Rates of seed attack}


Overall, apparent rates of seed attack at all study sites averaged $8.5 \pm 0.7 \%$ per plant species $(1,144$ plant species considered). However, apparent rate of seed attack, both for all plants surveyed and for the focal 10 plant families was significantly different and followed the series WAN $>$ KHC $>$ BCI (Table 1). The average number of seeds eaters reared per seed was also significantly different and followed the series KHC $>$ BCI $>$ WAN (Table 1). BCI had the lowest percentage of plant species attacked (by any insect guild) to plant species surveyed (64.1\%), followed by KHC (71.3\%) and WAN (77.4\%). Apparent percent seed attack was high for $\mathrm{C} 2$ syndromes at KHC and WAN (Table 2). When seeds were attacked, the abundance of seed eaters per seed was significantly different both between sites and seed syndromes (two way ANOVA, Table S6). This pattern was similar when considering the apparent rate of seed attack, with a stronger effect of seed syndrome than site (Table S6).

At BCI, $14 \%$ of the variance in the probability of rearing seed eaters (related to rates of seed attack, see Methods) from all plant species surveyed could be explained by the basal area of plant species and the seed rain (Table 3). At KHC, 17\% of the variance could be explained by basal area, fruit length and the sum of seeds collected, whereas at WAN only $9 \%$ of the variance was explained by the number of confamilial species, the abundance in the plot and the sum of seeds collected (Table 3). The results were largely similar once the effect of phylogeny had been controlled for, but some variables no longer had explanatory power (such as basal area and number of confamilial species) suggesting a degree of phylogenetic conservatism (Table S7). When seeds were attacked, it was difficult to evidence direct paths in the PPAs to the dependent variables, as models were not significant for BCI and KHC (Table S8). For Wanang, the number of seeds per fruit had a direct positive path to the average number of seeds eaters reared per unit seed (Fig. S8a), none of the independent variables influenced directly apparent rate of seed attack (Fig. S8b), and only sampling effort had some direct and relatively large influence on the number of seed eaters reared (Fig. S8c).

As indicated previously, the influence of the number of confamilial species was non-existent or weak in explaining the probability of rearing seed eaters from plant species (Table 3). Further, when plant species were attacked, there was no significant linear relation (or any notable non-linear relation) between the number of confamilial plant species and the average percentage of seed attack per plant genus at $\mathrm{BCI}\left(\mathrm{F}_{1,183}=0.51, \mathrm{p}=0.48\right)$, at $\mathrm{KHC}\left(\mathrm{F}_{1,109}=0.23, \mathrm{p}=0.64\right)$, or at WAN $\left(\mathrm{F}_{1,104}=2.53, \mathrm{p}=0.12\right)$.

\section{DISCUSSION}

\section{Synopsis of salient results}

Most of observed differences in our study system contrast BCI to other sites. BCI has a relatively low plant species richness, with a high proportion of shrubs and lianas and a high proportion of dry fruits. Basal area per plant species is high, as is the average seed weight, seed length and seed rain per plant species. A high proportion of seed eaters was reared from BCI samples. However, 
a low proportion of seed samples yielded insects (this may be partly due to the small size of BCI samples), apparent rate of seed attack was low and less plant species were attacked at BCI than at other sites. With reference to the questions formulated in the Introduction, our study indicated that (i) significant differences in insect assemblages exist at the study sites but it was difficult to predict the characteristics of these assemblages with plant and seed traits, including seed predation syndromes and fruit fleshiness. (ii) Seeds of rare trees were more likely to be attacked than those of common trees only at BCI. Guild proportionality in insect assemblages on common tree species was not conserved between sites. (iii) Rates of seed attack were not particularly low at the two floristically diverse sites and, within plant families, floristic richness had little apparent effects on rates of seed attack. As such these results suggest only weak community convergence of these insect assemblages at the intercontinental scale.

\section{Intercontinental comparison of insect assemblages feeding on seeds/fruits}

As far as we are aware our study represents the first intercontinental comparison with similar protocols of insect assemblages attacking seeds/fruits in tropical rainforests. Overall it indicated large differences in insect faunal composition, species richness and guild structure between the three study sites (question i). These patterns were similar when we restricted our dataset to the 10 focal plant families. Still, it can be argued that all insect guilds were represented at the three study sites, and that the main guilds were also reared from all seed syndromes. This observation can be interpreted as partial convergence (Korňan et al., 2013) in guild structure of the phylogenetically distinct insect assemblages at the three study sites.

However, the predictive power of seed syndromes was relatively weak. At BCI, where the availability of dry fruits was high, nearly $45 \%$ of insects reared were seed eaters, whereas this proportion was $<15 \%$ at KHC and WAN. In contrast, pulp eaters were proportionally better represented at $\mathrm{KHC}$ and WAN than at BCI. Further, at BCI dry seeds/fruits accumulated faster insect species than fleshy seed/fruits. In addition, the distribution of guilds appeared rather distinct for each category of seed syndromes. We conclude that for coarse functional comparison of insect assemblages between sites, the most distinctive dichotomy among our categories of seed syndromes is probably dry vs. fleshy fruits, although this variable cannot explain fine insect composition,

which is best explained by seed syndromes. This suggests that insect community convergence, either on dry or fleshy fruits, must be rather weak, if it exists at all. Gripenberg et al. (2018) showed that seed polyphenols on BCI are more influenced by the host successional stage (pionneer vs. shade-tolerant tree species) than by plant apparency (height of tree). It is conceivable that insect communities feeding on seed/fruits may also be more likely to convergence according to their host successional status. However, data were lacking in this study to accurately score the successional status of many plant species.

Still, several studies reported higher damage on dry fruits than on fleshy fruits (Janzen, 1969; Wright, 1990; Ctvrtecka et al., 2014). Our results partially support the hypothesis that the pulp of fleshy fruits may, in addition to being a reward for vertebrates 
disseminating fruits (Gautier-Hion, 1990), also act as protection from the attack of specific seed eaters (Bolmgren \& Eriksson, 2010). Specific adaptations may be required for insect ovipositing within or near the seed or for the insect larvae to reach the seed and start its development there in the presence of an abundant pulp (Wright, 1990). This certainly warrants further studies examining insect damage on different seed syndromes.

There were also overall differences between sites in the relative proportion of variance in insect faunal composition explained by plant traits and phylogeny. Our CCAs and PGLMMs results suggest that seed syndromes were important in shaping insect communities at BCI, while some seed traits were more important at $\mathrm{KHC}$, and plant phylogeny represented the best predictor in this regard at WAN. This high influence of phylogeny at WAN was probably due to closely related plants hosting more similar insect communities, while at BCI and KHC plant traits were more important in shaping insect communities and independently of plant phylogeny. Apart from seed syndromes, seed length and number of seeds per fruit appeared to influence most significantly the composition of insect assemblages. Ctvrtecka et al. (2016) reported that fruits attacked by Diptera are significantly larger than fruits attacked by Coleoptera and Lepidoptera. Other studies likewise reported a positive effect of seed size on seed eaters (Janzen, 1969; Ramírez \& Traveset, 2010; Sam et al., 2017). Overall we conclude that the composition and guild structure of insect assemblages feeding on seeds/fruits in tropical rainforests are partly shaped by seed predation syndromes, both at the local and regional scale, but that the factors shaping these assemblages are hard to identify.

Further, assemblages of insects feeding on seeds/fruits were richer at BCI, than at other sites, when we considered rarefaction of either the number of species sorted or the number of BINs sequenced. This observation is not an artifact of different sample size. Different studies targeting weevils and Lepidoptera indicated, despite larger sample sizes in both the number of plant species surveyed and the number of insect individuals reared, much less species-rich insect assemblage feeding on fruits/seeds in Papua New Guinea or Kenya than at BCI (Copeland et al., 2009; Ctvrtecka et al., 2014, 2016). This high insect species richness at BCI is at odd when considering other insect assemblages that have been studied at our study sites. Butterflies are more diverse at KHC or WAN than at BCI (Basset et al., 2013), and Geometridae and litter ants are also more species-rich at KHC than at BCI (Y. Basset et al., unpubl. data). We hypothesize that the high species richness of insect feeding on seeds/fruits at BCI may result from a conjunction of low plant species richness and high seed availability of dry fruits (see below; it may also be partly related to the high proportion and productivity of shrubs and liana) per plant species, which may favor such rich insect assemblages.

\section{Insect assemblages attacking the seeds of rare and common trees}

At BCI, more insects and seed eaters were reared from rare tree species than from common tree species, whereas these patterns did not exist at KHC and WAN. This appears to invalidate the resource concentration hypothesis (Root, 1973) and the higher 
likelihood of community convergence when abundant resources are available (Agrawal, 2017), in relation with question (ii). If we assume that seed eaters are very host-specific (Janzen, 1980) and that few hosts can escape them, then we would expect a concentration of damage (and reared seed eaters) on rare tree species and a dilution of damage over common tree species. This mechanism would require a very high insect host specificity and ability to locate hosts, as well as a large resource base easily traceable over which seed eaters may be satiated (Wright, 1990). During the period of our study, these conditions were more like to exist at BCI than at KHC or WAN.

\section{Seed attack}

Contrary to our predictions related to question (iii), the number of confamilial plant species appeared to be unimportant in explaining the apparent rate of seed attack per plant species. Species-rich plant family did not sustain higher seed attack than less diverse plant families. Our logistic regressions indicated that at BCI the probability of seeds of a plant species being attacked depended more on seed availability than on the measured seed traits of that plant species. This issue was less clear at KHC (possible effect of sample size) or WAN (low variance explained). Other traits, such as seed chemistry, nutritional quality, fruiting frequency and host phylogeny may be substantial in this regard (Janzen, 1969; Nakagawa et al., 2003; Ramírez \& Traveset, 2010). Resource availability may nevertheless represent a relatively important predictor of the probability of seed attack.

\section{Conclusions}

Studies of insect herbivores in tropical rainforests are few, and often focus on leaf-feeding insects (Lewinsohn et al., 2005). The assemblages of seed-eating insects studied here did not conform to two out of three general predictions (see Introduction) that were coined more specifically for leaf-feeding insect herbivores. As such, seed-eating insects may represent a rather distinct guild from insect herbivores that may be difficult to study but may have great potential to lower the fitness of their hosts (Lewis \& Gripenberg, 2008). As a further example, we note that in the tropics, increased damage or pathogens are often associated with increased rainfall (Coley \& Barone, 1996). Our study suggests that seed eaters may be better reared from dry fruits and perhaps at relatively dry tropical sites where fleshy fruits may be less prevalent (Kissling et al., 2009). However, biogeographical and host phylogenetical factors may complicate this pattern. 


\section{REFERENCES}

Agrawal, A.A. (2017) Toward a predictive framework for convergent evolution: integrating natural history, genetic mechanisms, and consequences for the diversity of life. The American Naturalist, 190, S1-S12.

Agrawal, A.A., \& Fishbein, M. (2006) Plant defense syndromes. Ecology, 87, S132-S149.

Anderson-Teixeira K.J., Davies S.J., Bennett A.C. Gonzalez-Akre E.B., Muller-Landau H.C., Wright S.J.,.. Zimmerman, J. (2014) CTFS-ForestGEO: a worldwide network monitoring forests in an era of global change. Global Change Biology, 21, 528549.

Barth, F.G. (1981) Insects and Flowers: The Biology of a Partnership. Princeton, Princeton University Press.

Basset, Y., Eastwood, R., Sam, L., Lohman, D.J., Novotny, V., Treuer, T., ... Osorio-Arenas, M.A. (2013) Cross-continental comparisons of butterfly assemblages in rainforests: implications for biological monitoring. Insect Conservation and Diversity, 6, 223-233.

Bittleston, L.S., Pierce, N.E., Ellison, A.M., \& Pringle, A. (2016) Convergence in multispecies interactions. Trends in Ecology \& Evolution, 31, 269-280.

Bolmgren, K. \& Eriksson, O. (2010) Seed mass and the evolution of fleshy fruits in angiosperms. Oikos, 119, 707-718.

Coley, P.D. \& Barone, J.A. (1996) Herbivory and plant defenses in tropical forests. Annual Review of Ecology, 27, 305-335.

Copeland, R.S., Luke, Q. \& Wharton, R.A. (2009) Insects reared from the wild fruits of Kenya. Journal of East African Natural History, 98, 11-66.

Ctvrtecka, R., Sam, K., Brus, E., Weiblen, G. D. \& Novotny, V. (2014) Frugivorous weevils are too rare to cause Janzen-Connell effects in New Guinea lowland rain forest. Journal of Tropical Ecology, 30, 521-535.

Ctvrtecka, R., Sam, K., Miller, S. E., Weiblen, G. D. and Novotny, V. (2016) Fruit sizes and the structure of frugivorous communities in a New Guinea lowland rainforest. Austral Ecology, 43, 228-237.

Díaz-Fleischer, F., Papaj, D. R., Prokopy, R. J., Norrbom A. L., \& Aluja, M. (2000) Evolution of fruit fly oviposition behavior. In Aluja, M., and Norrbom, A. L. (eds.), Fruit Flies (Diptera: Tephritidae): Phylogeny and Evolution of Behavior, pp. 811-841. Boca Raton, CRC Press.

Dray, S., Legendre, P., \& Peres-Neto, P. R. (2006) Spatial modelling: a comprehensive framework for principal coordinate analysis of neighbour matrices (PCNM). Ecological Modelling, 196, 483-493.

Feeny, P.P. (1976) Plant apparency and chemical defense. Recent Advances in Phytochemistry, 10, 1-40. 
Freckleton, R.P., Cooper, N. \& Jetz, W. (2011) Comparative methods as a statistical fix: the dangers of ignoring an evolutionary model. The American Naturalist, 178, E10-E17.

Fukami, T., Martijn Bezemer, T., Mortimer, S.R., \& Putten, W.H. (2005) Species divergence and trait convergence in experimental plant community assembly. Ecology Letters, 8, 1283-1290.

Gaston, K.J. (1994) Rarity. London, Chapman and Hall.

Gautier-Hion, A. (1990) Interactions among fruit and vertebrate fruit-eaters in an African tropical rain forest. Reproductive ecology of tropical forest plants (ed. Bawa, K.S. \& Hadley, M.), pp. 219-230. Boca Raton, CRC Press.

Gillespie, R. (2004) Community assembly through adaptive radiation in Hawaiian spiders. Science, 303, 356-359.

Gonzalez-Voyer, A. \& von Hardenberg, A. (2014) An Introduction to Phylogenetic Path Analysis. Chapter 8. In Garamszegi, L.Z. (ed.), Modern Phylogenetic Comparative Methods and Their Application in Evolutionary Biology. pp. 201-229. Berlin, Springer-Verlag.

Hendrix, S.D., Brown, V.K. \& Dingle, H. (1988) Arthropod guild structure during early old field succession in a new and old world site. The Journal of Animal Ecology, 57, 1053-1065.

Hsieh, T.C., Ma, K.H., \& Chao, A. (2016) iNEXT: an R package for rarefaction and extrapolation of species diversity (Hill numbers). Methods in Ecology and Evolution, 7, 1451-1456.

Inward, D.J., Davies, R.G., Pergande, C., Denham, A.J. \& Vogler, A.P. (2011) Local and regional ecological morphology of dung beetle assemblages across four biogeographic regions. Journal of Biogeography, 38, 1668-1682.

Irz, P., Michonneau, F., Oberdorff, T., Whittier, T.R., Lamouroux, N., Mouillot, D. \& Argillier, C. (2007) Fish community comparisons along environmental gradients in lakes of France and north-east USA. Global Ecology and Biogeography, 16, 350-366.

Ives, A.R. \& Helmus, M.R. (2011) Generalized linear mixed models for phylogenetic analyses of community structure. Ecological Monographs, 81, 511-525.

Janzen, D.H. (1969) Seed-eaters versus seed size, number, toxicity and dispersal. Evolution, 23, 1-27.

Janzen, D.H. (1980) Specificity of seed-attacking beetles in a Costa Rican deciduous forest. Journal of Ecology, 68, 929-952.

Kelly, C.K. \& Southwood, T.R.E. (1999) Species richness and resource availability: A phylogenetic analysis of insects associated with trees. Proceedings of the National Academy of Sciences of the United States of America, 96, 8013-8016.

Kissling, W.D., Böhning-Gaese, K. \& Jetz, W. (2009) The global distribution of frugivory in birds. Global Ecology and Biogeography, 18, 150-162.

Korňan, M., Holmes, R., Recher, H., Adamík, P. \& Kropil, R. (2013) Convergence in foraging guild structure of forest breeding bird assemblages across three continents is related to habitat structure and foraging opportunities. Community Ecology, 14, 89100. 
Kremen, C., Colwell, R.K., Erwin, T.L., Murphy, D.D., Noss, R.A., \& Sanjayan, M.A. (1993) Terrestrial arthropod assemblages: their use in conservation planning. Conservation Biology, 7, 796-808.

Lawton, J.H. (1984) Non-competitive populations, non-convergent communities, and vacant niches: the herbivores of bracken. In Strong, D.L.Jr., Simberloff, D., Abele, L.G., Thistle, A.B. (eds), Ecological communities: Conceptual issues and the evidence, pp. 67-100. Princeton, Princeton University Press.

Lewinsohn, T.M., Novotny, V. \& Basset, Y. (2005) Insects on plants: diversity of herbivore assemblages revisited. Annual Review of Ecology, Evolution and Systematics, 36, 597-620.

Lewis, O.T. \& Gripenberg, S. (2008) Insect seed predators and environmental change. The Journal of Applied Ecology, 45, 15931599.

Mahler, D.L., Weber, M.G., Wagner, C.E., \& Ingram, T. (2017) Pattern and process in the comparative study of convergent evolution. The American Naturalist, 190, S13-S28.

Mares, M.A. (1993) Desert rodents, seed consumption, and convergence. BioScience, 43, 372-379.

Messina, F. J. (1984) Influence of cowpea pod maturity on the oviposition choices and larval survival of a bruchid beetle Callosobruchus maculatus. Entomologia experimentalis et applicata, 35, 241-248.

Moran, C.V.\& Southwood, T.R.E. (1982) The guild composition of arthropod communities in trees. Journal of Animal Ecology, 51, 289-306.

Nakagawa, M., Itioka, T., Momose, K., Yumoto, T., Komai, F., Morimoto, K., ... Inoue, T. (2003) Resource use of insect seed predators during general flowering and seeding events in a Bornean dipterocarp rain forest. Bulletin of Entomological Research, 93, $455-466$.

Novotny, V., Basset, Y., Miller, S.E., Weiblen, G.D., Bremer, B., Cizek, L. \& Drozd, P. (2002) Low host specificity of herbivorous insects in a tropical forest. Nature, 416, 841-844.

Oksanen J., Blanchet, F.G., Kindt, R. et al. (2011) Vegan: community ecology package. R package version 1.17-6. Vienna, R Foundation for Statistical Computing.

Pearse, W.D., Cadotte, M.W., Cavender-Bares, J., Ives, A.R., Tucker, C.M., Walker, S.C. \& Helmus, M.R. (2015) pez: phylogenetics for the environmental sciences. Bioinformatics, 31, 2888-2890.

Petschenka, G., Wagschal, V., Tschirnhaus, M.V., Donath, A., \& Dobler, S. (2017) Convergently evolved toxic secondary metabolites in plants drive the parallel molecular evolution of insect resistance. The American Naturalist, 190, S29-S43.

Ramírez, N. \& Traveset, A. (2010) Predispersal seed-predation by insects in the Venezuelan central plain: overall patterns and traits that determine its incidence. Perspectives in Plant Ecology, Evolution and Systematics, 12, 193-209.

Ratnasingham, S. \& Hebert, P.D.N. (2013) A DNA-based registry for all animal species: the Barcode Index Number (BIN) system. PloS one, 8, e66213. Doi: 10.1371/journal.pone.0066213 PMID: 23861743 
Ricklefs, R.E. \& Travis, J. (1980) A morphological approach to the study of avian community organization. The Auk, 97, 321338.

Root, R.B. (1973) Organization of a plant-arthropod association in simple and diverse habitats: the fauna of collards (Brassica oleracea). Ecological Monographs, 43, 95-124.

Sam, K., Ctvrtecka, R., Miller, S.E., Rosati, M.E., Molem, K., Damas, K., Gewa, B. and Novotny, V. (2017) Low host specificity and abundance of frugivorous Lepidoptera in the lowland rain forests of Papua New Guinea. PloS one, 12, p.e0171843.

Samuels, C.L., \& Drake, J.A. (1997) Divergent perspectives on community convergence. Trends in Ecology \& Evolution, 12, 427-432.

Schluter, D. (1986) Tests for similarity and convergence of finch communities. Ecology, 67, 1073-1085.

Segar, S.T., Pereira, R.A., Compton, S.G., \& Cook, J.M. (2013) Convergent structure of multitrophic communities over three continents. Ecology Letters, 16, 1436-1445.

Smith, B., \& Wilson, J.B. (2002) Community convergence: ecological and evolutionary. Folia Geobotanica, 37, 171-183.

Strong, D.R., Lawton, J.H. \& Southwood, T.R.E. (1984) Insects on Plants: Community Patterns and Mechanisms. Oxford, Blackwell Scientific Publications.

ter Braak, C.J. \& Smilauer, P. (2012) Canoco reference manual and user's guide: software for ordination, version 5.0. Ithaca, Microcomputer Power.

van der Bijl, W. (2017) phylopath: Easy phylogenetic path analysis in R.” bioRxiv. doi: 10.1101/212068, R package version 1.0.0.

Watts, C.H., Clarkson, B.R., \& Didham, R.K. (2008) Rapid beetle community convergence following experimental habitat restoration in a mined peat bog. Biological Conservation, 141, 568-579.

Warton, D.I \& Hui, F.K.C. (2011) The arcsine is asinine: the analysis of proportions in ecology. Ecology, 92, 3-10.

Webb, C. O. \& Donoghue, M. J. (2005) Phylomatic: tree assembly for applied phylogenetics. Molecular Ecology Notes, 5, 181183.

Winemiller, K.O. (1991) Ecomorphological diversification in lowland freshwater fish assemblages from five biotic regions. Ecological Monographs, 61, 343-365.

Wright, S.J. (1990) Cumulative satiation of a seed predator over the fruiting season of its host. Oikos, 58, 272-276.

Wright S.J., Calderón O., Hernandéz, A. \& Paton, S. (2004) Are lianas increasing in importance in tropical forests? A 17-year record from Panama. Ecology, 85, 484-489. 
SUPPORTING INFORMATION:

Appendix S1. Supplementary methods.

Appendix S2. Supplementary results.

Table S1. Characteristics of study sites and plant samples.

Table S2. Taxonomic composition of the insect material.

Table S3. Matrices of similarity between study sites.

Table S4. Summary results of CCAs.

Table S5. Summary results of PGLMMs.

Table S6. Results of two way ANOVAs considering rates of seed attack.

Table S7. Results of logistic regressions after controlling for the effect of host plant phylogeny.

Table S8. Results of the phylogenetic path analyses.

Fig. S1. Models used for the phylogenetic path analyses.

Fig. S2. Proportion of individuals reared at each study site.

Fig. S3. Proportion of individuals reared from each seed syndrome category at each study site.

Fig. S4. Plots of guilds and plant species in the first two axes of CA for the three study sites.

Fig. S5. Species accumulation curves for insects detailed by sites.

Fig. S6. Species accumulation curves for insects detailed by seed syndromes.

Fig. S7. Contrasts in common and rare tree species for species accumulation and guild structure.

Fig. S8. Significant models of phylogenetic path analysis in Wanang.

\section{BIOSKETCH}

Yves Basset is interested in the community ecology of tropical arthropods. Author contributions: Y.B., C.D., R.C., S.G., O.T.L., O.K., P.K. conceived the ideas; R.C., H.B., J.W.B., S.B., B.A.B., A.I.C., S.D., M.K., S.E.M., G.E.M., V.N., N.P., P.P., D.Q.,R.K.B., W.S. M.S., E.J.V., W.W., Y.W., G.W., J.S.W. contributed insect and plant data; Y.B., C.D., R.C., S.T.S., P.K. analyzed the data and led the writing. 
Table 1. Salient characteristics of plant traits and insect variables measured across sites. Means are reported with se in brackets. Differences between means are tested by Kruskal-Wallis tests (significantly different groups indicated by different letters, Dwass-Steel post hoc tests), differences between proportions by Chi-square tests. Details about study sites and plant samples are reported in Table S1.

\begin{tabular}{|c|c|c|c|c|}
\hline Variable & BCI & КHC & WAN & $\mathbf{p}$ \\
\hline \multicolumn{5}{|l|}{ Plant traits (average per plant species): } \\
\hline Average no. of stems per tree species per ha & $13.02(2.80)$ & $7.97(1.06)$ & $9.17(1.02)$ & 0.065 \\
\hline Average basal area per tree species per ha $(\mathrm{m}-2 \mathrm{x}$ ha- 1$)$ & $0.133(0.02)^{\mathrm{a}}$ & $0.087(0.01)^{\mathrm{b}}$ & $0.052(0.01)^{\mathrm{c}}$ & $<0.001$ \\
\hline Average seed rain per tree species (dry g x m-2 x yr-1) & $0.53(0.139)^{\mathrm{a}}$ & $0.009(0.005)^{\mathrm{b}}$ & $0.015(0.004)^{\mathrm{b}}$ & $<0.001$ \\
\hline Average seed fresh weight $(\mathrm{g})$ & $25.6(5.0)^{\mathrm{a}}$ & $18.3(3.1)^{\mathrm{a}}$ & $11.4(1.3)^{\mathrm{b}}$ & $<0.001$ \\
\hline Average seed length (mm) & $39.7(2.4)^{\mathrm{a}}$ & $28.0(1.1)^{b}$ & $22.3(0.9)^{\mathrm{c}}$ & $<0.01$ \\
\hline Average no. of seed eaters reared per seed & $0.12(0.03)^{\mathrm{a}}$ & $0.23(0.14)^{\mathrm{b}}$ & $0.10(0.04)^{\mathrm{a}}$ & $<0.001$ \\
\hline Apparent rate of seed attack (\% seed attacked) & $5.4(0.43)^{\mathrm{a}}$ & $9.4(0.89)^{b}$ & $12.5(0.98)^{\mathrm{b}}$ & $<0.001$ \\
\hline Apparent rate of seed attack ( $\%)$ - 10 focal plant families & $6.1(0.77)^{\mathrm{a}}$ & $10.1(1.33)^{\mathrm{b}}$ & $12.2(1.33)^{\mathrm{b}}$ & 0.013 \\
\hline \multicolumn{5}{|l|}{ Insect samples: } \\
\hline Total number of insects reared & 27,610 & 17,555 & 35,434 & - \\
\hline Total number of insects reared -10 focal plant families & 12,736 & 8,851 & 24,033 & - \\
\hline Proportion of samples with insects reared (\%) & 29.4 & 59.4 & 51.2 & $<0.001$ \\
\hline Proportion of samples with seed eaters reared $(\%)$ & 12.6 & 10.9 & 12.7 & 0.141 \\
\hline Mean insects reared per sample & $2.6(0.15)^{\mathrm{a}}$ & $7.6(0.55)^{b}$ & $7.5(0.39)^{\mathrm{b}}$ & $<0.001$ \\
\hline Mean seed eaters reared per sample & $1.17(0.11)$ & $1.08(0.19)$ & $1.07(0.13)$ & 0.15 \\
\hline Mean seed eaters reared per attacked sample & $9.3(0.82)$ & $9.8(1.62)$ & $8.5(0.95)$ & 0.15 \\
\hline Mean insects reared per seed & $0.51(0.04)^{\mathrm{a}}$ & $1.71(0.16)^{b}$ & $0.53(0.04)^{\mathrm{a}}$ & $<0.001$ \\
\hline Mean insects reared per g weight & $0.23(0.09)^{\mathrm{a}}$ & $0.11(0.01)^{\mathrm{b}}$ & $0.08(0.01)^{\mathrm{c}}$ & $<0.001$ \\
\hline
\end{tabular}


Table 2. Number of individual insects reared from different seed syndromes, detailed for each study site. Sum refer to the total of insect reared, SE \% to percentage of seed eaters and $\mathrm{AT} \%$ to mean percent apparent rate of attack and (se).

\begin{tabular}{|c|c|c|c|c|c|c|c|c|c|}
\hline Seed syndrome* & $\begin{array}{l}\text { BCI } \\
\text { Sum }\end{array}$ & SE \% & АT\% & $\begin{array}{l}\text { KHC } \\
\text { Sum }\end{array}$ & SE \% & AT\% & $\begin{array}{l}\text { WAN } \\
\text { Sum }\end{array}$ & SE \% & AT\% \\
\hline \multicolumn{10}{|l|}{ A. Drupe (one seed per fruit) } \\
\hline \multicolumn{10}{|l|}{ A1. Fleshy drupe } \\
\hline A1.1 Fleshy drupe with thick mesocarp ( $>5 \mathrm{~mm})$ & 1125 & 32.2 & $\begin{array}{l}12.5 \\
(0.96)\end{array}$ & 1293 & 4.0 & $\begin{array}{l}11.8 \\
(1.7)\end{array}$ & 7676 & 12.4 & $\begin{array}{c}11.5 \\
(1.06)\end{array}$ \\
\hline A1.2 Fleshy drupe with thin mesocarp $(<5 \mathrm{~mm})$ & 5655 & 62.1 & $\begin{array}{l}10.5 \\
(0.63)\end{array}$ & 3388 & 8.6 & $\begin{array}{c}9.2 \\
(0.96)\end{array}$ & 7092 & 10.0 & $\begin{array}{c}11.1 \\
(0.82)\end{array}$ \\
\hline \multicolumn{10}{|l|}{ A2. Non-fleshy drupe } \\
\hline A2.1 Non-fleshy drupe with thick mesocarp ( $>5 \mathrm{~mm})$ & 1424 & 30.1 & $\begin{array}{c}13.1 \\
(1.23)\end{array}$ & 275 & 5.5 & $\begin{array}{c}12.1 \\
(3.19)\end{array}$ & 2844 & 24.1 & $\begin{array}{c}17 \\
(2.07)\end{array}$ \\
\hline A2.2 Non-fleshy drupe with thin mesocarp $(<5 \mathrm{~mm})$ & 2748 & 51.6 & $\begin{array}{l}11.6 \\
(0.84)\end{array}$ & 1735 & 12.4 & $\begin{array}{l}18.4 \\
(2.59)\end{array}$ & 1116 & 31.1 & $\begin{array}{c}17 \\
(2.72)\end{array}$ \\
\hline \multicolumn{10}{|l|}{ B. Fleshy or non-fleshy fruit with multiple seeds } \\
\hline B1 Fleshy indehiscent fruit with multiple seeds & 3834 & 48.0 & $\begin{array}{c}7.1 \\
(0.69)\end{array}$ & 6388 & 7.2 & $\begin{array}{l}14.6 \\
(1.18)\end{array}$ & 5930 & 18.5 & $\begin{array}{c}14.3 \\
(1.22)\end{array}$ \\
\hline $\begin{array}{l}\text { B2 Non-fleshy dehiscent fruit with multiple seeds } \\
\text { (dehiscence typically across multiple axes) }\end{array}$ & 7239 & 21.7 & $\begin{array}{c}8.6 \\
(0.55)\end{array}$ & 593 & 3.9 & $\begin{array}{c}9.3 \\
(2.2)\end{array}$ & 9665 & 2.5 & $\begin{array}{c}8.4 \\
(0.89)\end{array}$ \\
\hline \multicolumn{10}{|l|}{ C. Dry fruit/seed, often winged } \\
\hline C1 Dry winged seed that do not develop in capsule & 521 & 49.7 & $\begin{array}{c}7.3 \\
(0.86)\end{array}$ & 436 & 40.4 & $\begin{array}{c}16 \\
(2.11)\end{array}$ & 29 & 0 & $\begin{array}{c}1.3 \\
(1.25)\end{array}$ \\
\hline $\begin{array}{l}\text { C2 Multiple dry seeds (with or without wings) that do } \\
\text { develop in capsule/pod (opening across one axis) }\end{array}$ & 4766 & 33.4 & $\begin{array}{c}7.6 \\
(0.51)\end{array}$ & 1654 & 22.2 & $\begin{array}{c}28.7 \\
(4.34)\end{array}$ & 462 & 3.7 & $\begin{array}{c}32.2 \\
(6.16) \\
\end{array}$ \\
\hline
\end{tabular}

* Recombined categories for some analyses: drupes = A1.1, A1.2, A2.1, A2.2; "fleshy fruits" = A1.1, A1.2, B1; "dry fruits" $($ achenes $)=\mathrm{A} 2.1, \mathrm{~A} 2.2, \mathrm{~B} 2, \mathrm{C} 1, \mathrm{C} 2$. 
Table 3. Results of stepwise binary logistic regression describing the probability of rearing seed eaters for all plant species surveyed. Models are detailed separately for each study site (n indicates the number of plant species). For similar analyses controlling for the effect of host plant phylogeny, see Table S7.

\begin{tabular}{lcccccc}
\hline Model/Parameter & Estimate & $\mathbf{s d}$ & $\mathbf{t}$ & $\mathbf{P r}(>|\mathbf{t}|)$ & $\mathbf{R}^{2}$ & $\mathbf{n}$ \\
\hline BCI & - & - & - & - & 0.140 & 204 \\
Constant & -0.434 & 0.185 & -2.340 & 0.020 & - & - \\
Basal area & 0.050 & 0.024 & 2.096 & 0.037 & - & - \\
Seed rain & 1.313 & 0.653 & 2.011 & 0.046 & - & - \\
& & & & & & \\
KHC & - & - & - & - & 0.167 & 156 \\
Constant & -2.608 & 0.449 & -5.810 & 0.000 & - & - \\
Basal area & 0.058 & 0.030 & 1.917 & 0.057 & - & - \\
Fruit length & 0.035 & 0.010 & 3.496 & 0.001 & - & - \\
Sum of seeds collected & 0.003 & 0.001 & 2.879 & 0.005 & - & - \\
& & & & & & \\
WAN & - & - & - & - & 0.086 & 240 \\
Constant & -0.831 & 0.288 & -2.889 & 0.004 & - & - \\
No. of confamilial species & 0.012 & 0.008 & 1.543 & 0.124 & - & - \\
Abundance in plot & 0.000 & 0.000 & 1.453 & 0.148 & - & - \\
Sum of seeds collected & 0.001 & 0.000 & 2.550 & 0.011 & - & - \\
\hline
\end{tabular}




\section{FIGURE LEGENDS}

Fig. 1. Plot of the average proportion of individuals of (a) taxa and (b) guilds reared per sample (all samples considered) for each study site. For taxa and guilds, proportions of particular taxa/guilds across sites are all significantly different (Kruskal-Wallis tests, all with $\mathrm{p}<0.05)$. Figures above bars indicate, for each site, the percentage of samples in which a taxon or guild was present. Note that because values are averaged across all samples, proportions are rather small.

Fig. 2. Proportion of the number of individuals reared from each seed syndrome category, detailed for each guild and each study site.

Fig. 3. Plot of the variance in composition of insect species (circles; singletons excluded from analyses) explained by significant ecological variables (plant traits) and plant phylogeny in the first and second canonical axes of the CCA for (a) BCI, (b) KHC and (c) WAN. Continuous variables are coded as red vectors with closed arrows, factorial predictors as symbols. For the later, plant life form is coded as blue squares, centroids of seed syndromes as red triangles (empty = fleshy fruits, solid = dry fruits). Plant phylogenetic axes are coded as green vectors with open arrows. The matrix sizes (plant species $\mathrm{x}$ insect species) and \% of variability explained by each axis and their efficiency are indicated in the plots.

Fig. 4. Abundance of all insects and seed eaters (means and s.e.) on common and rare tree species at each study site. 

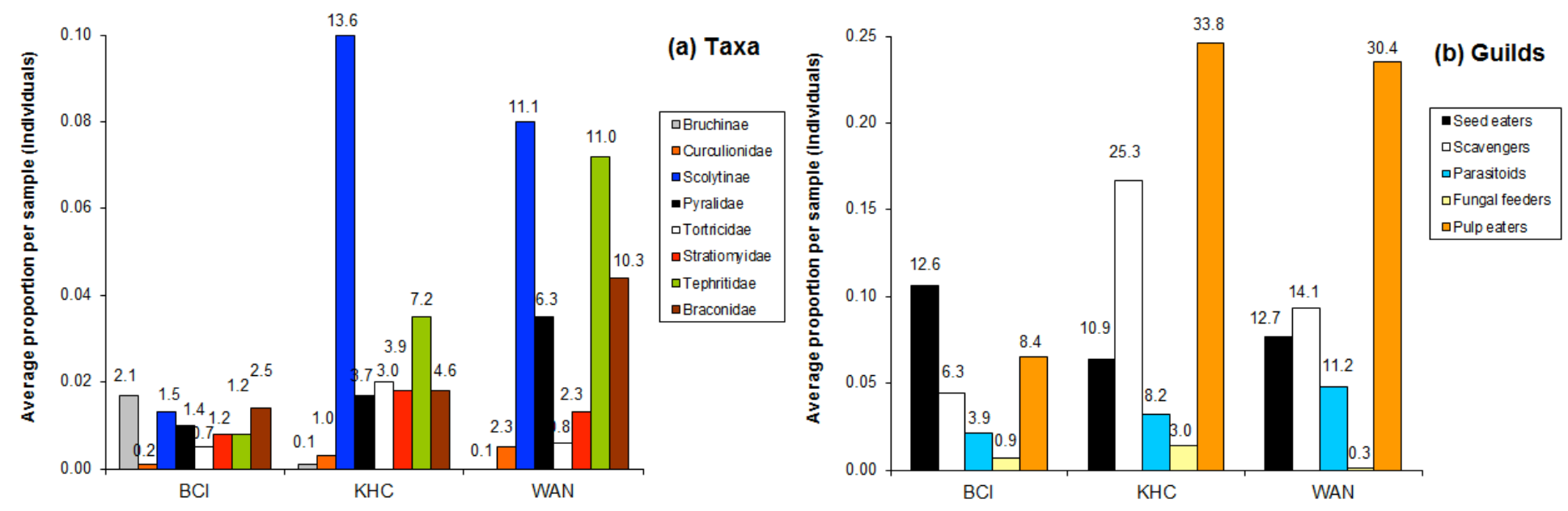

Fig. 1. Plot of the average proportion of individuals of (a) taxa and (b) guilds reared per sample (all samples considered) for each study site. For taxa and guilds, proportions of particular taxa/guilds across sites are all significantly different (Kruskal-Wallis tests, all with $\mathrm{p}<0.05$ ). Figures above bars indicate, for each site, the percentage of samples in which a taxon or guild was present. Note that because values are averaged across all samples, proportions are rather small.
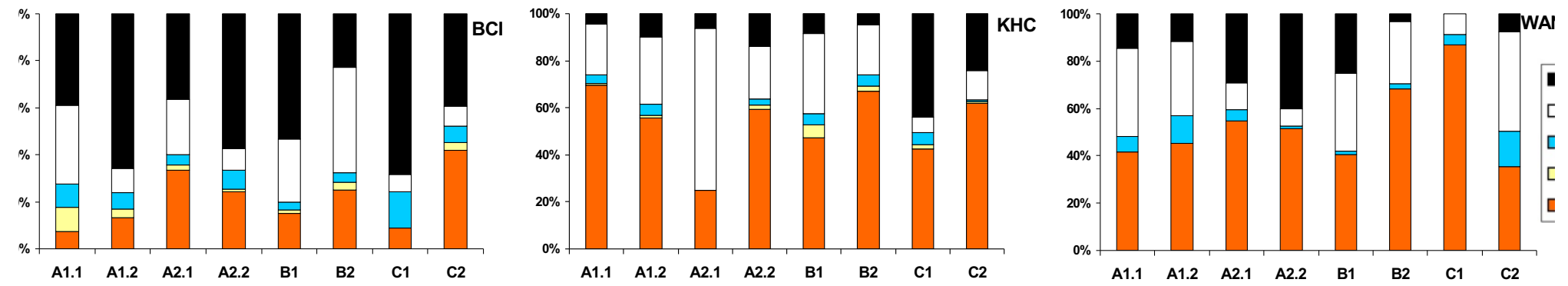

Fig. 2. Proportion of the number of individuals reared from each seed syndrome category, detailed for each guild and each study site. 

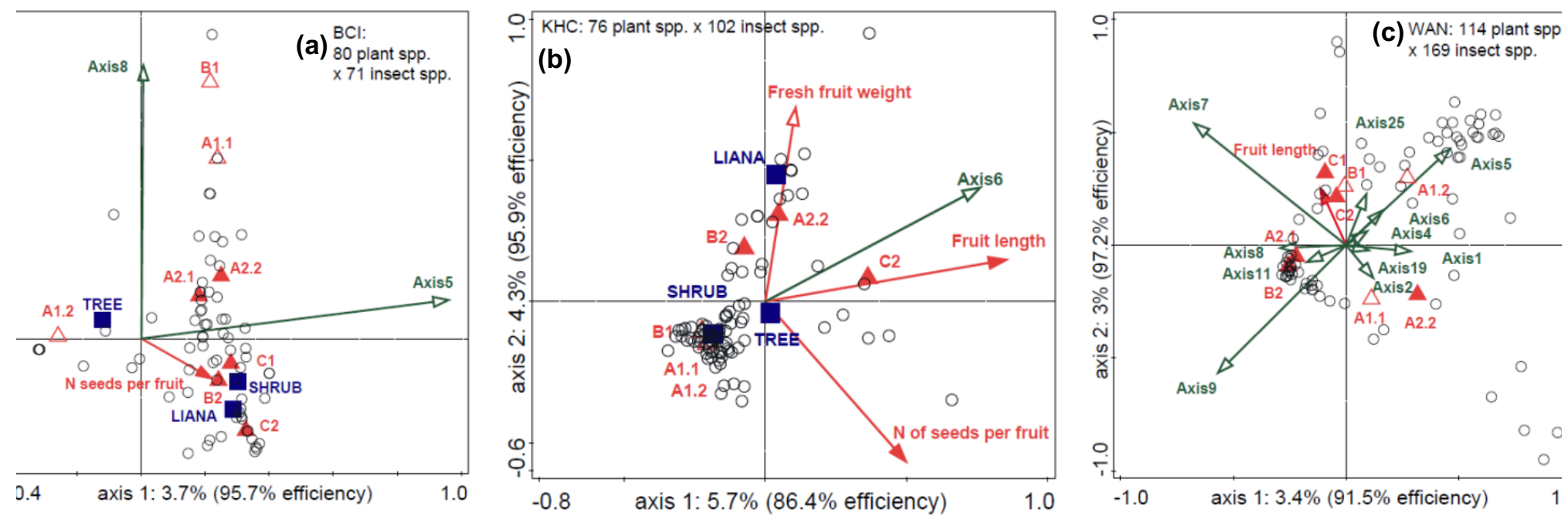

Fig. 3. Plot of the variance in composition of insect species (circles; singletons excluded from analyses) explained by significant ecological variables (plant traits) and plant phylogeny in the first and second canonical axes of the CCA for (a) BCI, (b) KHC and (c) WAN. Continuous variables are coded as red vectors with closed arrows, factorial predictors as symbols. For the later, plant life form is coded as blue squares, centroids of seed syndromes as red triangles (empty = fleshy fruits, solid = dry fruits). Plant phylogenetic axes are coded as green vectors with open arrows. The matrix sizes (plant species $\mathrm{x}$ insect species) and $\%$ of variability explained by each axis and their efficiency are indicated in the plots. 


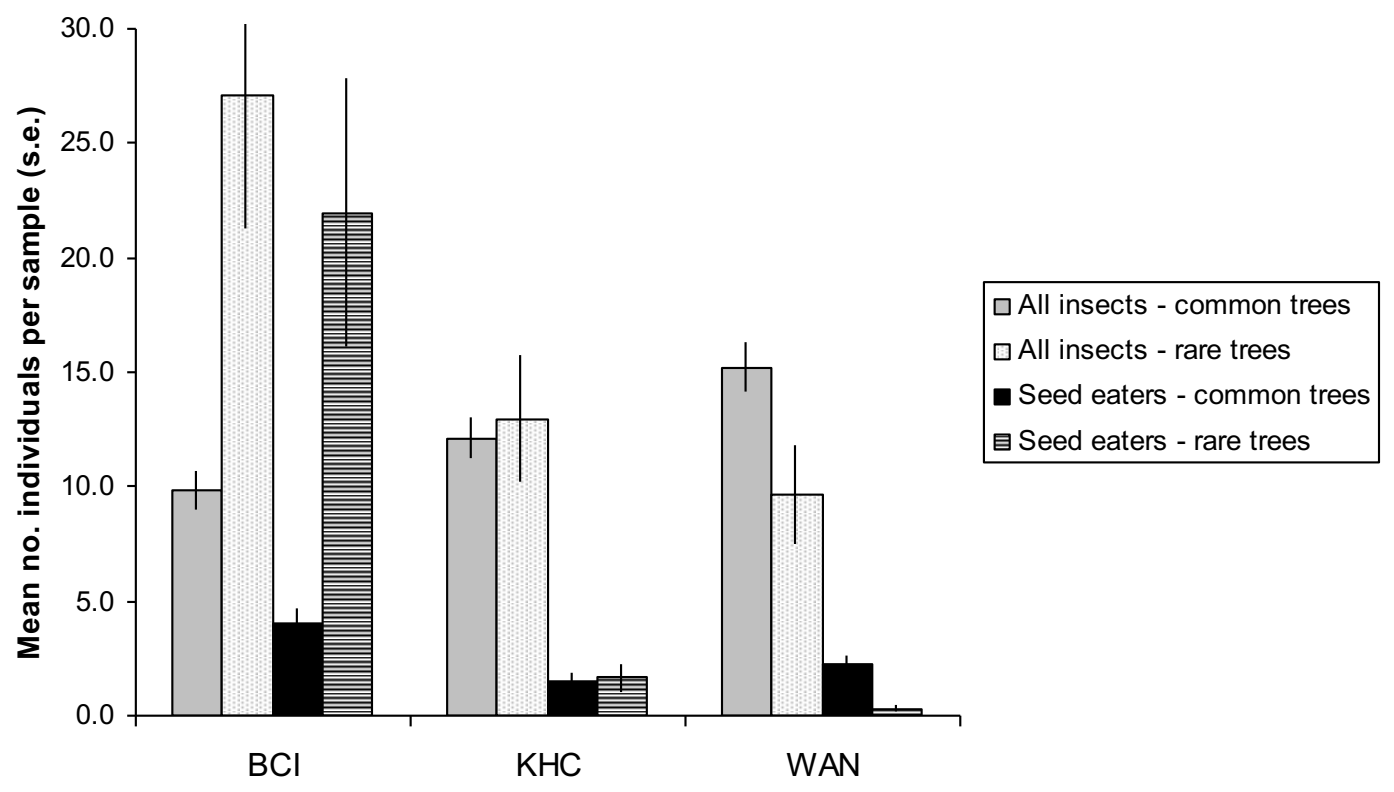

Fig. 4. Abundance of all insects and seed eaters (means and s.e.) on common and rare tree species at each study site. 